\title{
Total Diz Artroplastisi Uygulanan Hastalarda Turnike Kullanımının Alt Ekstremite Venöz Sistem Üzerine Etkisi
}

\section{Tourniquet Effect on the Lower Extremity Venous System in the Patients Undergoing Total Knee Arthoplasty}

\author{
Gökhan CANSABUNCU1 (D), Fatih GÜMÜȘ² \\ ${ }^{1}$ Bartın Devlet Hastanesi, Ortopedi ve Travmatoloji Kliniği, Bartın, Türkiye \\ ${ }^{2}$ Bartın Devlet Hastanesi, Kalp ve Damar Cerrahisi Kliniği, Bartın, Türkiye
}

ORCID ID: Gökhan Cansabuncu 0000-0002-0036-6382, Fatih Gümüș 0000-0001-6687-2731

Bu makaleye yapılacak atıf: Cansabuncu G, Gümüș F. Total Diz Artroplastisi Uygulanan Hastalarda Turnike Kullanımının Alt Ekstremite Venöz Sistem Üzerine Etkisi. Med J West Black Sea. 2021;5(1):50-56.

Sorumlu Yazar

Gökhan Cansabuncu

E-posta

cansabuncu@gmail.com
Geliș Tarihi

16.08.2020

Revizyon Tarihi

03.12.2020

Kabul Tarihi

10.12.2020
Öz

Amaç: Total diz artroplastisi (TDA) sonrasında meydana gelen alt ekstremite venöz sistem kaynaklı patolojileri incelemek ve cerrahisi sırasında uygulanan pnömatik turnikenin venöz damarların üzerine olan etkisini değerlendirmektir.

Gereç ve Yöntemler: Primer diz osteoartriti nedeni ile turnike kullanılarak TDA uygulanan 42 (Grup 1) , turnike kullanılmadan TDA uygulanan 40 (Grup 2) olmak üzere toplam 82 hasta retrospektif olarak değerlendirilip çalışmaya alındı. İki grup arasında preoperatif vena sefana magna (VSM) çapı, klinik venöz yetmezlik derecesi ve intraoperatif operasyon süresi, turnike uygulama zamanı, uygulanan turnike basıncı, ortalama sistolik kan basıncı, uygulanan anestezi yöntemi parametreleri kıyaslandı.

Bulgular: İki grup arasında venöz tromboembolik hastalık (VTEH) açısından fark bulunmadı. Grup 1'de postoperatif bacak ödemi anlamlı derecede yüksekti $(p=0.02)$. Çok değişkenli regresyon analizine göre; turnike kullanılan hasta grubunda, turnike süresi $>49.5 \mathrm{dk}$ [odds değeri (OD) $2.48,95 \%$ güven aralığı (GA) 0.48-0.91], turnike basıncı ( $\mathrm{mmHg})>275 \mathrm{mmHg}$ [OD 1.98, 95\% GA 0.23-0.84], preoperatif VSM reflü $>1$ sn [OD 1.23, 95\% GA 0.32-0.93], ameliyat süresi $>65$ dk [OD 1.13, 95\% GA 0.11-0.58] bacak ödemi gelişimi açısından bağımsız risk faktörü olarak belirlendi.

Sonuç: TDA gibi alt ekstremiteyi ilgilendiren ortopedik girişimlerde turnike kullanımının hastaya göre bireyselleştirilmesinin; turnike süresi, turnike basıncı ve preoperatif venöz vasküler sistemin detaylı değerlendirilmesinin, postoperatif bacak ödemi ve diğer komplikasyonlardan kaçınma açısından önem arz ettiğini düşünmekteyiz.

Anahtar Sözcükler: Total diz artroplastisi, Turnike kullanımı, Tromboemboli, Venöz yetmezlik, Bacak ödemi

\section{ABSTRACT}

Aim: The aim of the study is to investigate the pathologies related with lower extremity venous system following total knee arthroplasty (TKA) and to evaluate the effect of tourniquet usage on the venous vascular system.

Materials and Methods: The study cohort comprised 82 patients who underwent TKA due to primary knee osteoarthritis and was divided into the patients performed TKA with using tourniquet (Group 1, $\mathrm{n}=42$ patients) and without using tourniquet (Group 2, $\mathrm{n}=40$ patients). Two groups were compared in the respect of parameters inluding preoperative great saphenous vein (GSV) diameter, clinical venous insufficieny level, operation time, tourniquet application time, tourniquet pressure, mean systolic blood pressure and performed type of anesthesia. 
Results: No significant difference was determined between the groups in respect of venous thromboembolic disease (VTED. Postoperative leg swelling was found to be significantly higher in the group 1 ( $p=0.02$ ). Tourniquet application time $>49.5$ min [odds ratio (OR) $2.48,95 \%$ confidance interval $(\mathrm{Cl})$ 0.48-0.91], tourniquet pressure $>275 \mathrm{mmHg}$ [OR $1.98,95 \% \mathrm{Cl} 0.23-0.84$ ], preoperative GSV reflux $>1$ sec [OR $1.23,95 \% \mathrm{Cl} 0.32-0.93$ ], operation time $>65$ min [OR 1.13, 95\% $\mathrm{Cl} 0.11-0.58$ ] were identified as independent risk factors for leg swelling following TKA

Conclusion: We think that it is very important to individualize the tourniquet application in the orthopedic interventions involving lower extremity such as TKA and to evaluate tourniquet time, tourniquet pressure and preoperative venous vascular system for avoiding postoperative leg swelling and other related complications.

Keywords: Total Knee Arthroplasty, Tourniquet application, Thromboemboli, Venous insufficiency, Leg swelling

\section{GiRiş}

Günümüzde pnömatik turnike Total Diz Artroplastisi (TDA) sırasında sıklıkla kullanılmaktadır. Turnike ile çalışmak cerraha kansız bir cerrahi alan yaratarak daha iyi bir görüş alanı ve ayrıca daha iyi bir çimento-kemik yüzey ilişkisi sunar. Ancak turnikenin sinir hasarı (1), damar yaralanması (2), kas hasarı (3), postoperatif şişlik ve sertlik (4) ve venöz tromboembolik hastalıklar (VTEH) (5) gibi yan etkilerinden dolayı kullanımı günümüzde hâlen tartışmalıdır. Bundan dolayı dikkatli bir hasta muayenesi ile birlikte turnikenin kullanım prensiplerini anlayarak uygulanması turnikeye bağlı komplikasyonları en aza indirmek için önemlidir. Pnömatik turnikenin basıncı ve süresi hastanın yaşına, kan basıncına ve ekstremitenin boyutuna göre değişmektedir (6).

TDA sonrası derin ven trombozu (DVT) ve pulmoner emboli (PE) gibi VTEH'ın insidansının \%25 civarı olduğu tahmin edilmektedir (7-8). Semptomatik DVT ve PE'nin ise hastalarının \% 0.8 ila 1.8'inde görüldüğü bildirilmiştir (9-10). Ancak pnömatik turnikenin venöz yetmezlik üzerine etkisi bilinmemektedir.

Bu çalışmadaki amacımız TDA sonrasında meydana gelen alt ekstremite venöz sistem kaynaklı patolojileri incelemek ve cerrahi sırasında uygulanan pnömatik turnikenin venöz damarlarının üzerine olan etkisini değerlendirmektir.

\section{GEREÇ ve YÖNTEMLER}

Çalışmamız Bartın Devlet Hastanesi Ortopedi ve Travmatoloji Kliniği'nde 2 yıllık bir dönemde (Ocak 2018 ve Aralık 2019) diz osteoartriti nedeni ile TDA yapılan 117 hasta üzerinde uygulanan retroprospektif bir çalışmadır. Çalışmaya, Zonguldak Bülent Ecevit Üniversitesi Tıp Fakültesi Etik Kurulu'nun onayı (2020/16-12) alınarak başlanmıştır.

Unilateral TDA uygulanıp ameliyat öncesi ve ameliyat sonrası dönemde bacak çapı ölçülmüş olan ve yine ameliyat öncesi duplex ultrasonography (SonoSite S-Nerve, Bothell, WA) ile vena sefena magna çapı (VSM), derin ve perforan ven yetmezlik dereceleri değerlendirilmiş olan hastalar çaIışmaya dahil edildi.

Bilateral TDA uygulanan (25 hasta), periferik vasküler hastalığı (2 hasta), geçirilmiş venöz yetmezlik cerrahisi (7 has- ta) ve venöz trombo embolik (1 hasta) hastalık öyküsü olan hastalar çalışmaya dahil edilmedi.

Buna göre turnike kullanılarak TDA uygulanan 42 (Grup 1), turnike kullanılmadan TDA uygulanan 40 (Grup 2) olmak üzere toplam 82 hasta çalışmaya alındı.

Hastalara ait operasyon süresi, turnike uygulama zamanı, uygulanan turnike basıncı, intraoperatif ortalama sistolik kan basıncı, uygulanan anestezi yöntemi ve komorbid hastalıklar dosyalar retrospektif olarak incelenerek değerlendirildi (Tablo 1).

DVT profilaksisi için tüm hastalara enoksaparin sodyum 4000 IU (Oksapar 4000 anti-Xa IU/0.4 ml ${ }^{\circledR}$, Koçak Farma, İstanbul, Türkiye) ameliyat öncesi 12. saatte başlanıp ameliyat sonrası 35 güne tamamlanacak şekilde günde tek doz olarak uzatılmış profilaksi şeklinde uygulandı. Postoperatif 1. günde hemovak dren çekildi. $18 \mathrm{mmHg}$ basınçlı diz üstü anti embolik çorap giydirilerek hastalar mobilize edildi.

Hastaların postoperatif 3. ayda yapılan kontrollerinde kayıt altına alınan alt ekstremite venöz yetmezlik dereceleri, CEAP sınıflandırmaları, ayrıca patella üst polünün $10 \mathrm{~cm}$ proksimalinden ve patella alt polünün $10 \mathrm{~cm}$ distalinden ölçülmüş olan uyluk ve kruris çapları değerlendirildi. Bacak çapı ölçümleri arasında $2 \mathrm{~cm}$ üzerindeki farklar şişlik ve ödem açısından klinik olarak anlamlı kabul edildi (11-13). Elde edilen veriler preoperatif değerlendirmeler ile kıyaslandı. Ayrıca VTEH açısından hastaların hastaneye başvuruları retrospektif olarak tarand.

Çalışmada elde edilen bulgular değerlendirilirken, istatistiksel analizler için IBM SPSS Statistics 22 (IBM SPSS, Türkiye) yazılım programı kullanıldı. Verilerin değerlendirilmesinde tanımlayıcı istatistikler yapıldı. Sürekli değişkenler ortalama \pm standart sapma (SS) olarak gösterildi ve kategorik değişkenler ise frekans ve yüzde olarak verildi. Verilerin normal dağılıma uygunluğunun tespitinde Shapiro-Wilk testi kullanıldı. Kategorik değişkenleri karşılaştırmak için Pearson v2 veya Fisher' Exact test kullanıldı. Sürekli değişkenler ise Student's t test veya Mann-Whitney U testi kullanılarak karşılaştırıldı. Karşılaştırma sonucu turnike kullanan hastalarda postoperatif bacak ödemi gelişimine katkıda bulunabilecek tekli değişkenlerden anlamlı seviyeye ulaşanlar çoklu 
lojistik regresyon analizine sokuldu. Regresyon analizi sonucu da anlamlılığı devam eden prediktif değerler için Receiver-operating characteristic (ROC) eğrileri çizildi.

\section{BULGULAR}

Çalışmamızdaki hasta grupları arasında yaş, cinsiyet, vücut kitle indeksi gibi demografik veriler açısından anlamlı fark bulunmadı. Çalışmaya alınan hastalara eşlik eden hipertansiyon, diabet, obezite, hiperlipidemi ve vasküler olamayan AF gibi komorbid hastalıklar açısından iki grup arasında istatistiksel olarak anlamlı fark bulunmadı (Tablo 1).

Preoperatif değerlendirmelerde çalışmaya alınan hastalarda grupları arası vena sefana magna (VSM) çapları, yetmezlik dereceleri ve CEAP sınıflamaları açısından istatistiksel olarak anlamlı fark bulunmadı (Tablo 1).
İntraoperatif veriler incelendiğinde, hastalara uygulanan anestezi türü ve ameliyat süreleri açısından iki grup arasında anlamlı fark bulunmadı (Tablo 2).

Postoperatif dönemde hastalar VTEH ve alt ekstremite venöz sistem açısından değerlendirildiğinde Grup 1'de 1 hastada PE, 3 hastada ise DVT'ye rastlanmış iken Grup 2'de yalnızca 1 hastada DVT saptanmış olup PE'ye rastlanmamıştır. Hastalar bacak çapları açısından değerlendirildiğinde $2 \mathrm{~cm}$ ve üzerindeki çap farkı bacak ödem olarak kabul edildi ve iki grup arasında bu açıdan anlamlı fark bulundu $(p=0.02)$ (Tablo 2).

Postoperatif dönemde bacak ödeminin anlamlı olarak yüksek bulunduğu Grup 1 grubunda bacak ödemi olan ve olmayan hastalar alt grup olarak ayrıca değerlendirildiğinde turnike süresi, turnike basıncı, intraoperatif ortalama sistolik

Tablo 1: Hastalara ait demografik veriler

\begin{tabular}{|c|c|c|c|c|}
\hline & $\begin{array}{l}\text { Tüm hastalar } \\
\mathrm{n}=82(\%)\end{array}$ & $\begin{array}{c}\text { Grup } 1 \\
\text { Turnike (+) } n=42(\%)\end{array}$ & $\begin{array}{c}\text { Grup } 2 \\
\text { Turnike (-) } n=40(\%)\end{array}$ & P değeri \\
\hline Yaş (yıl) & $67.1 \pm 5.8$ & $67.9 \pm 6.2$ & $66.2 . \pm 5.2$ & 0.41 \\
\hline Cinsiyet(Erkek) & 38 (46.3) & $20(47.6)$ & $18(45.0)$ & 0.33 \\
\hline VKI $\left(\mathrm{kg} / \mathrm{m}^{2}\right)$ & $29.2 \pm 4.1$ & $29.5 \pm 4.2$ & $28.8 \pm 5.2$ & 0.36 \\
\hline Preoperatif VSM çapı (cm) & $3.47 \pm 0.83$ & $3.42 \pm 0.26$ & $3.55 \pm 0.18$ & 0.24 \\
\hline \multicolumn{5}{|l|}{ Preoperatif VSM yetmezlik derecesi } \\
\hline - Reflü süresi <0.5 sn & $41(50.0)$ & $22(52.3)$ & $19(47.5)$ & 0.27 \\
\hline - Reflü süresi 0.5-1 sn & $21(25.6)$ & $11(26.1)$ & $10(25.0)$ & 0.55 \\
\hline - Reflü süresi > 1 sn & $20(24.3)$ & $9(21.4)$ & $11(27.5)$ & 0.39 \\
\hline \multicolumn{5}{|l|}{ Preoperatif CEAP sınıflaması } \\
\hline$\cdot \mathrm{CO}$ & $10(12.1)$ & $4(9.5)$ & $6(15.5)$ & 0.11 \\
\hline - C1-2 & $15(18.2)$ & $8(19.04)$ & $7(17.5)$ & 0.19 \\
\hline$\cdot \mathrm{C} 3$ & $40(48.7)$ & $21(50.0)$ & $19(47.5)$ & 0.28 \\
\hline - C4-6 & $17(20.7)$ & $9(21.4)$ & $8(20.0)$ & 0.56 \\
\hline \multicolumn{5}{|l|}{ Etiyoloji } \\
\hline - Primer & $82(100.0)$ & $42(100.0)$ & $40(100.0)$ & 0.77 \\
\hline \multicolumn{5}{|l|}{ Anatomi } \\
\hline - Yüzeyel/derin VY & $60(73.1)$ & $33(78.5)$ & $27(67.5)$ & 0.23 \\
\hline - Derin & $22(26.8)$ & $9(21.4)$ & $13(32.5)$ & 0.31 \\
\hline \multicolumn{5}{|l|}{ Patofizyoloji } \\
\hline - Yalnız reflü & $82(100.0)$ & $42(100.0)$ & $40(100.0)$ & 0.77 \\
\hline \multicolumn{5}{|l|}{ Ek hastalıkları } \\
\hline - DM & $23(28.04)$ & $13(30.9)$ & $10(25.0)$ & 0.21 \\
\hline - Hipertansiyon & $51(62.1)$ & $21(50.0)$ & $30(75.0)$ & 0.65 \\
\hline - Hiperlipidemi & $38(46.3)$ & $17(40.4)$ & $21(52.5)$ & 0.54 \\
\hline - Obezite & $41(50.0)$ & $18(42.8)$ & $23(57.5)$ & 0.19 \\
\hline - Valvuler olmayan AF & $21(25.6)$ & $9(21.4)$ & $12(30.0)$ & 0.14 \\
\hline
\end{tabular}

VKi: Vücut kitle indeksi, VSM: Vena sefana magna, CEAP: Klinik, etyolojik, anatomik, patofizyolojik 
Tablo 2: Gruplar arası değerlendirmeler

\begin{tabular}{|c|c|c|c|}
\hline & $\begin{array}{c}\text { Grup } 1 \\
\text { Turnike (+) } n=42(\%)\end{array}$ & $\begin{array}{c}\text { Grup } 2 \\
\text { Turnike (-) } n=40(\%)\end{array}$ & P değeri \\
\hline Derin ven trombozu & $3(7.1)$ & $1(2.5)$ & - \\
\hline Pulmoner emboli & $1(2.3)$ & $0(0.0)$ & - \\
\hline Postoperatif bacak ödemi & $26(61.9)$ & $1230.0)$ & c $0.02 \Delta *$ \\
\hline Ameliyat süresi (dk) & $68.2 \pm 14.9$ & $74.2 \pm 16.2$ & 0.14 \\
\hline \multicolumn{4}{|l|}{ Anestezi tipi } \\
\hline - Rejyonel & $40(95.2)$ & $37(92.5)$ & 0.27 \\
\hline - Genel & $2(4.7)$ & $3(7.5)$ & 0.53 \\
\hline
\end{tabular}

dk: dakika, ${ }^{\Delta}$ Student $t$ Testi; ${ }^{\psi}$ Man Whitney U Testi; ${ }^{*} p<0,05,{ }^{* *} p<0,01$

Tablo 3: Turnike kullanılan hastalarda bacak ödemine etki eden faktörler

\begin{tabular}{lccc}
\hline Değişkenler & Bacak ödemi (+) $\mathbf{n = 2 6 ~ ( \% ) ~}$ & Bacak ödemi (-) $\mathbf{n = 1 6 ~ ( \% ) ~}$ & P değeri \\
\hline Turnike süresi (dk) & $53.4 \pm 6.3$ & $47.3 \pm 2.16$ & $\mathbf{0 . 0 4 1} \Delta^{*}$ \\
\hline Turnike basıncı (mmHg) & $294.6 \pm 26.8$ & $273.2 \pm 31.3$ & $\mathbf{0 . 0 1 8} \Delta^{*}$ \\
\hline İntraoperatif OSKB (mmHg) & $154.8 \pm 16.3$ & $136.2 \pm 21.8$ & $\mathbf{0 . 0 3 2} \Delta^{*}$ \\
\hline Ameliyat süresi (dk) & $72.6 \pm 12.1$ & $63.2 \pm 18.3$ & $\mathbf{0 . 0 2 3} \Delta^{*}$ \\
\hline Preoperatif VSM reflü > 1 sn & $20(76.9)$ & $4(25.0)$ & $\mathbf{0 . 0 1 3} \Delta^{*}$ \\
\hline
\end{tabular}

Dk: Dakika, sn: Saniye, VSM: Vena sefana magna, ${ }^{\Delta}$ Student t Testi, ${ }^{\psi}$ Man Whitney U Testi, ${ }^{*} p<0,05,{ }^{* *} p<0,01$

Tablo 4: Postoperatif bacak ödemi için bağımsız belirteçler

\begin{tabular}{llcc}
\hline & P değeri & Odds değeri & \%95 GA \\
\hline Turnike süresi $>49.5 \mathrm{dk}$ & $0.033 \Delta^{*}$ & 2.48 & $0.48-0.91$ \\
\hline Turnike basıncı $(\mathrm{mmHg})>275 \mathrm{mmHg}$ & $0.011 \Delta^{*}$ & 1.98 & $0.23-0.84$ \\
\hline Preoperatif VSM reflü $>1 \mathrm{sn}$ & $0.024 \Delta^{*}$ & 1.23 & $0.32-0.93$ \\
\hline Ameliyat süresi $>65 \mathrm{dk}$ & $0.046 \Delta^{*}$ & 1.13 & $0.11-0.58$
\end{tabular}

Dk: Dakika, VSM: Vena sefana magna, sn: Saniye, ${ }^{\Delta}$ Student t Testi, ${ }^{\psi}$ Man Whitney U Testi, ${ }^{*} p<0,05,{ }^{* \star} p<0,01$

kan basıncı (OSKB), ameliyat süresi ve preoperatif VSM yetmezlikleri açısından anlamlı fark bulundu (Tablo 3).

P değeri 0,05’ten küçük olan tüm parametreleri çok değişkenli regresyon analizine koyduğumuzda; turnike süresi $>49.5$ dk [odds değeri (OD) 2.48, \%95 güven aralığı (GA) 0.48-0.91], turnike basıncı $(\mathrm{mmHg})>275 \mathrm{mmHg}$ [OD 1.98, $\% 95$ GA 0.23-0.84], preoperatif VSM reflü $>1$ sn [OD 1.23, $\% 95$ GA 0.32-0.93], ameliyat süresi $>65 \mathrm{dk}$ [OD 1.13, \%95 GA 0.11-0.58] turnike kullanımı sonrası bacak ödemi açısından bağımsız prediktif risk faktörü olarak bulundu (Tablo 4).

Bu bağımsız risk faktörleri için ROC eğrisi çizildi. Turnike süresi ve turnike basıncı parametreleri, turnike kullanılan hastalarda TDA sonrası bacak ödemini predikte etme açısından; sırayla kesim noktaları $49.5 \mathrm{dk}$ ve $275 \mathrm{mmHg}$, olmak üzere en yüksek ROC eğrisinin altında kalan alana (AUC, turnike süresi için AUC: 0.73 ve turnike basıncı için AUC: 0.68) ulaştı (Şekil 1A,B).

\section{TARTIŞMA}

Çalışmamız bilinen literatürde primer diz osteoartrit nedeni ile TDA uygulanan hastalarda turnike kullanımının postoperatif dönemde meydana gelen venöz tromboembolik hastalıkların yanı sıra alt ekstremite venöz sistem üzerine etkisini araştıran ilk çalışmadır. Yapmış olduğumuz çalışmamızda DVT ve PE turnike kullanılan hasta grubunda istatistiksel olarak anlamı olmamakla birlikte daha fazla görüldü. Yine turnike kullanılan grupta postoperatif bacak ödemi anlamlı derecede yüksek bulundu. Ayrıca turnike kullanılan grupta turnike süresinin 49.5 dakika üzerinde olması, turnike basıncının $275 \mathrm{mmHg}$ üzerinde kullanılması, ameliyat süresinin 65 dakikadan fazla sürmesi ve preoperatif VSM reflü süresinin 1 saniyeden fazla olması postoperatif dönemde bacak ödemi oluşturması açısından daha riskli olarak bulunmuştur. 

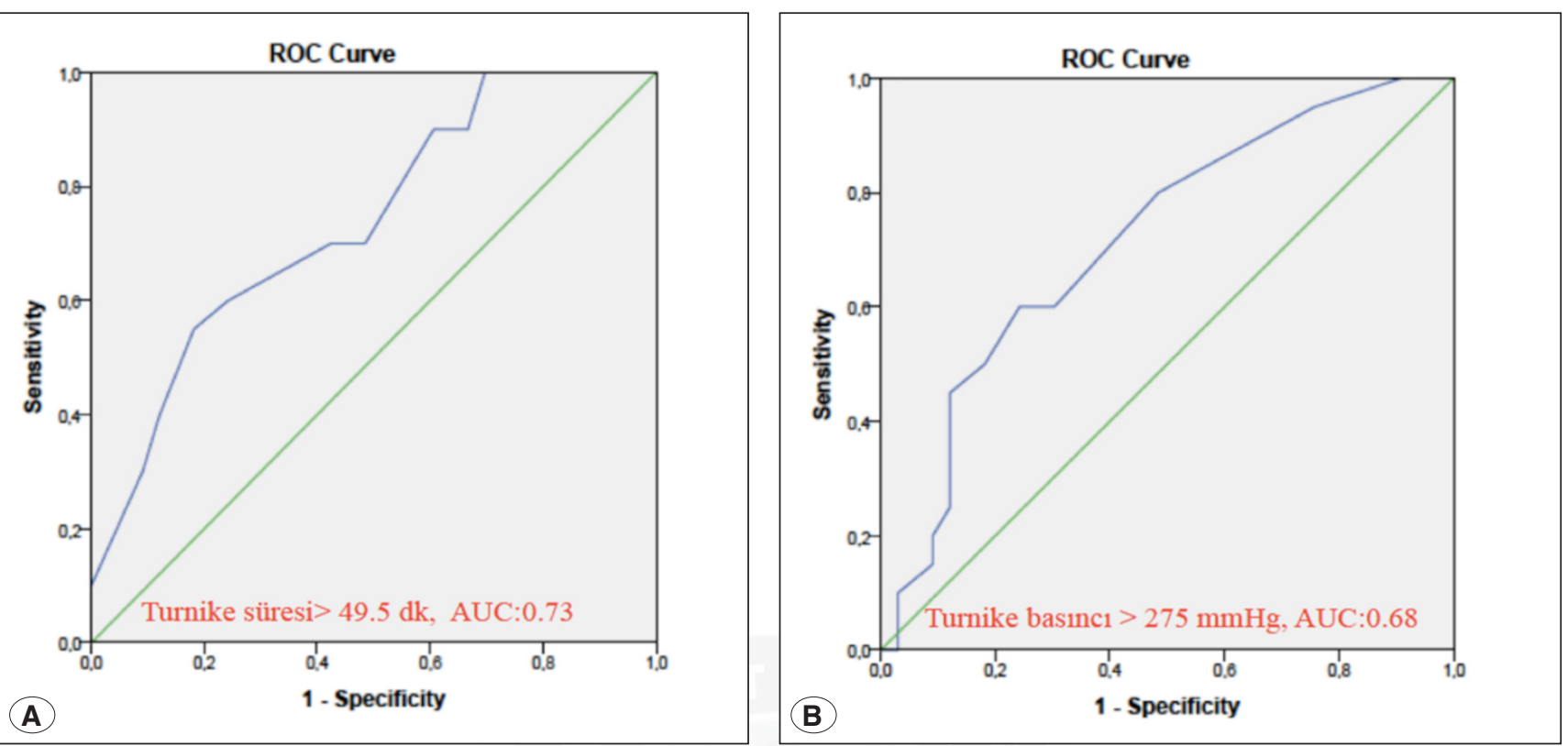

Şekil 1: A) Turnike süresi, B) Turnike basıncı için ROC (Receiver operating characteristic) eğrileri

VTEH total diz artroplastisinin ciddi bir komplikasyonudur. Son yıllarda, profilaksinin yaygın kullanımı ile birlikte VTEH görülme oranlarında ciddi düşüşler saptanmıştır. Profilaksinin amacı, olguları VTEH'ın ciddi ve ölümcül bir klinik tablosu olan PE gelişiminden korumaktır.

1884'de tanımlanmış olan Virchow'un triadındaki vasküler endoteliyal hasar, staz ve hiperkoagülabilite gibi patofizyolojik süreçlerin yokluğunda VTEH genellikle gelişmez. Alt ekstremite patolojileri nedeni ile ameliyat edilen ortopedi hastalarının neredeyse tamamında ise bu patofizyolojik olayların hepsi mevcuttur.

Turnike kullanımı, immobilizasyon ve yatak istirahati ile staza neden olurken ekstremitenin cerrahi olarak manipülasyonu vasküler endoteliyal hasara neden olur. TDA gibi kemik çimentosu kullanılan ameliyatlarda polimetilmetakrilat (PMMA) hiperkoagülabiteyi artırır. Bu nedenle, ortopedik cerrahi geçiren ve ortopedik travmalı hastalarda, risk faktörlerinin iyi değerlendirilmesi ve VTEH profilaksisi ile ilgili kılavuzlara uyulması çok önemlidir (14).

TDA sonrası düşük molekül ağırlıklı heparin (DMAH) uygulanan hastalarda DVT oranları \%50 oranında azalmaktadır; 10-14 günlük kısa süreli ya da 27-35 günlük uzatılmış profilaksiyle kanama riskinde belirgin artış gözlenmemektedir (15). Kliniğimizde TDA uygulanan hastalara DVT profilaksisi için enoksaparin sodyum 4000 IU (Oksapar 4000 anti-Xa IU/0.4 ml ${ }^{\circledR}$, Koçak Farma, İstanbul, Türkiye) ameliyat öncesi 12. saatte başlanıp ameliyat sonrası 35 güne tamamlanacak şekilde günde tek doz olarak uzatılmış profilaksi şeklinde uygulanmaktadır. Ayrıca hastaların tamamı postoperatif 1. gün $18 \mathrm{mmHg}$ basınçlı diz üstü anti embolik çorap giydirilerek hastalar mobilize edilmektedir. Bu prosedürlerin uygulandığı hastaların değerlendirildiği çalışmamızda 3'ü turnike kullanılan grupta olmak üzere toplam 4 hastada DVT saptanmışken, yalnızda 1 hastada PE tespit edildi.

TDA uygulanan hastalarda, anestezi tipinin VTE gelişimi üzerine olan etkisinin araştırıldığı çalışmalarda genel anesteziye oranla rejyonel anestezinin DVT riskini azaltmada etkili olduğu gösterilmiştir (16). DVT riskindeki bu azalmanın olası mekanizması; epidural anestezi sonrası oluşan sempatik blokajın alt ekstremitede vazodilastasyona, artmış arteriyel akıma ve venöz boşalmaya neden olarak venöz göllenmeyi azaltmasıdır (17). Yapılan randomize kontrollü çalışmalarda, kullanılan antikoagülan profilaksisinden bağımsız olarak spinal ya da epidural anestezinin genel anesteziye oranla DVT insidansını \%50 oranında azalttığı gösterilmiştir (18). Çalışmamızda turnike kullanılan grupta 40 (\%95.2) hastada, turnike kullanılmayan grupta ise 37 (\%92.5) hastada rejyonel anestezi kullanılmış olup gruplar arasında anlamlı fark bulunmamasına rağmen VTEH sayısı turnike kullanılan grupta daha fazla saptanmıştır.

Turnike kansız bir cerrahi alan yaratarak cerraha daha iyi bir görüş alanı sağlar ve intraoperatif kanama miktarını azaltır. Bu gibi etkilerine rağmen erken dönemde diz eklem hareketlerini azaltması (19), venöz tromboemboli (20) ve hipoksiye bağlı yara problemleri (21) gibi komplikasyonlardan dolayı literatür turnike kullanımı konusunda tartışmalıdır. Aglietti ve ark.'nın yaptığı randomize kontrollü bir çalışmada, turnike kullanımının venöz göllenmeye yol açmasının yanı sıra fibrinolizisi de artırdığı, sonuç olarak turnike kullanılmayan hastalara göre daha az tromboz geliştiği gösterilmiştir (22). 
Yapmış olduğumuz çalışmada da turnike kullanılmayan grupta VTEH sayısının daha az görülmesi turnikenin tromboemboli üzerine risk faktörü olabileceğini düşündürmektedir. Ancak literatürde turnike kullanımının DVT insidansını artırmadığı bildiren çalışmalar da mevcuttur (23).

Turnike kullanımı ameliyat edilen bacakta kan akımını keserek kuru bir cerrahi alan dolayısıyla daha iyi bir görüş sağladığından çoğu cerrah tarafından tercih edilmektedir. Yapmış olduğumuz çalışmada turnike uygulanan grupta ortalama ameliyat süresi $68.2 \pm 14.9$ dakika iken turnike kullanılmayan hasta grubunda bu değer $74.2 \pm 16.2$ dakika bulunmakla birlikte bu fark istatistiksel olarak anlamlı bulunmamıştır. Turnike uygulanan gruptaki daha kısa olan ameliyat sürelerinin turnikenin cerraha sağladığı daha iyi görüşten kaynaklandığını düşünmekteyiz.

Turnike şişirilirken uygulanacak basınç hastanın yaşına, kan basıncına, uygulanacak ekstremiteye ve uygulanan ekstremitenin çapına göre değişmektedir (6). Uygulanacak basınç konusunda farklı metodlar tanımlanmıştır. Bunlardan biri üst ekstremite için sistolik kan başıncına 50-75 mmHg, alt ekstremitede ise 100-150 mmHg eklenmesidir (24). Yaptığımız çalışmada turnike kullanılan gruptaki hastalarda cerrahiye başlamadan önce ölçülen sistolik kan basıncı ortalama $154.8 \pm 16.3 \mathrm{mmHg}$ olup intraoperatif ortalama turnike basıncı $294.6 \pm 26.8$ mmHg olarak bulunmuştur. Mevcut değerlerimizin literatür doğrultusunda turnikeye bağlı oluşabilecek komplikasyonlar açısından güvenli sınırlar içerisinde olduğu görülmüştür.

Literatürde turnike kullanımının VTEH'a predispozan olması konusunda farklı sonuçlar bildiren çalışmalar olup turnikenin uygulandığı basınç miktarının ve basınç süresinin alt ekstremite venöz damarlarında yetmezliğe bir etki yaratıp yaratmadığı konusunda bir bilgi yoktur. Bu amaçla çaış̧mamızda venöz yetmezlik - bacak ödemi ilişkisi ayrıca incelendi. İki grup arasında preoperatif değerlendirmelerde çalışmaya alınan hastalarda grupları arası VSM çapları, yetmezlik dereceleri ve CEAP sınıflamaları açısından istatistiksel olarak anlamlı fark bulunmazken ameliyat sonrası dönemde turnike uygulanan grupta 26 (\%61.9), turnike uygulanmayan grupta 12 (30.0\%) hastada bacak ödemi tespit edildi $(p=0.02)$. Bu sonuçlar doğrultusunda turnikenin venöz yetmezliğe ve dolayısıyla bacak ödemine etki edebilecek bir risk faktörü olacağı düşünülebilir.

Bu doğrultuda turnike kullanılan grupta bacak ödemi gelişmiş 26 (\%61.9) ve ödem gelişmemiş 16 (\%38.1) hasta alt grup olarak tekrar değerlendirildi. Sonuç olarak yapılan değişkenli regresyon analizinde turnike süresinin 49.5 dakikadan uzun olması, turnike basıncının 275 mmHg'dan yüksek olması, ameliyat süresinin 65 dakikadan fazla sürmesi ve ayrıca preoperatif VSM reflü süresinin 1 saniye üzerinde olması olarak turnike kullanımı sonrası bacak ödemi açısından bağımsız prediktif değer olarak bulundu.
Yapmış olduğumuz çalışmamızın başlıca kısıtlaması çaışmanın retrospektif olması ve hasta sayısının az olması söylenebilir. Daha geniş serilerle yapılacak prospektif çalışmalarda VTEH konusunda farklı sonuçlara ulaşılabilir. Çaışmamızın retrospektif doğasından dolayı postoperatif dönemde hastaların VSM çaplarının ve yetmezlik derecesinin USG aracılığıyla ölçülmemiş olması da bir diğer kısıtlama olabilir.

Sonuç olarak turnike kullanımının avantajlarının ve dezavantajlarının daha iyi ortaya konulması için yeni çalışmalar ihtiyaç olduğunu düşünmekteyiz. Ayrıca sunduğumuz çalışmanın turnikenin venöz yetmezlik ve bacak ödemi ile ilişkisini araştıracak yeni çalışmalara da ışık tutacağına inanmaktayız.

\section{Teşekkür}

Çalışma boyunca yardımlarını ve desteklerini esirgemeyen Bartın Devlet Hastanesi Ortopedi ve Travmatoloji Kliniği doktorları Op. Dr. Ömer Tansel ALIŞ’a, Op. Dr. Orhan YILDIZ'a, Op. Dr. Fethi BíLGiN'e ve Op. Dr. Volkan Tolga TEKBAŞ’a teşekkür ederiz.

\section{Yazar Katkı Beyanı}

Makalenin tasarlanması, yazılması: Gökhan Cansabuncu, Verilerin elde edilmesi, istatistiksel analiz, son gözden geçirme: Fatih Gümüş.

\section{Çıkar Çatışması}

Yazarlar arasında çıkar çatışması yoktur.

\section{Finansal Destek}

Hiçbir kurum veya firmadan finansal destek alınmamıştır.

\section{Etik Kurul Onayı}

Çalışma öncesi Zonguldak Bülent Ecevit Üniversitesi Tıp Fakültesi Hastanesi etik kurulundan 2020/16-12 nolu etik kurul onayı alınmıştır.

Hakemlik Süreci

Yazı hakemlerin değerlendirmeleri sonrası yayınlanmaya uygun bulunmuş ve kabul edilmiştir.

\section{KAYNAKLAR}

1. Guanche CA, Rorabeck $\mathrm{CH}$, Kennedy JC. Tourniquet-induced tibial nerve palsy complicating anterior cruciate ligament reconstruction. Arthroscopy 1995;11:620-622.

2. Hagan PF, Kaufman EE. Vascular complication of knee arthroplasty under tourniquet. A case report. Clin Orthop 1990; 257:159-161.

3. Shenton DW, Spitzer SA, Mulrennan BM. Tourniquet-induced rhabdomyolysis. A case report. J Bone Joint Surg Am 1990;72:1405-1406. 
4. Klenerman L. Is a tourniquet really necessary for knee replacement? J Bone Joint Surg Br 1995;77:174-175.

5. Dai WL, Lin ZM, Shi ZJ, Wang J. Venous Thromboembolic Events after Total Knee Arthroplasty: Which Patients Are at a High Risk? [published online ahead of print, 2019 May 24]. J Knee Surg. 2019;10.1055/s-0039-1688962. doi:10.1055/s-0039-1688962

6. Murphy C, Winter D, Bouchier-Hayes D. Tourniquet injuries: Pathogenesis and modalities for attenuation. Acta Orthopaedica Belgica 2005;71(6):635.

7. Deitelzweig S. Preventing venous thromboembolic events after total hip arthroplasty: New developments in clinical practice. Hosp Pract 2012;40(02):79-87.

8. O'Reilly RF, Burgess IA, Zicat B. The prevalence of venous thromboembolism after hip and knee replacement surgery. Med J Aust 2005;182(04):154-159

9. Falck-Ytter Y, Francis CW, Johanson NA, Curley C, Dahl OE, Schulman S, Ortel TL, Pauker SG, Colwell Jr CW. Prevention of VTE in orthopedic surgery patients: Antithrombotic Therapy and Prevention of Thrombosis, 9th ed: American College of Chest Physicians Evidence-Based Clinical Practice Guidelines. Chest 2012; 141(2, Suppl):e278S-e325S

10. Zhang ZH, Shen B, Yang J, Zhou ZK, Kang PD, Pei FX. Risk factors for venous thromboembolismof total hip arthroplasty and total knee arthroplasty: A systematic review of evidences in ten years. BMC Musculoskelet Disord 2015;16(1):24.

11. Munk S, Jensen NJ, Andersen I, Kehlet H, Hansen TB. Effect of compression therapy on knee swelling and pain after total knee arthroplasty. Knee Surg Sports Traumatol Arthrosc 2013;21(2):388-392.

12. Pinsornsak $P$, Chumchuen $S$. Can a modified Robert Jones bandage after knee arthroplasty reduce blood loss? A prospective randomized controlled trial. Clin Orthop Relat Res 2013;471(5):1677-1681.

13. Matthews CN, Chen AF, Daryoush T, Rothman RH, Maltenfort $M G$, Hozack WJ. Does an elastic compression bandage provide any benefit after primary TKA? Clin Orthop Relat Res 2019;477(1):134-144.
14. Koçyiğit A, Atilla B. Venöz tromboembolizm risk faktörlerinin değerlendirilmesi. TOTBID Dergisi 2019;18:473-481.

15. Comp PC, Spiro TE, Friedman RJ, Whitsett TL, Johnson GJ, Gardiner GA, Landon GC, Jové M. Prolonged enoxaparin therapy to prevent venous thromboembolism after primary hip or knee replacement. J Bone Joint Surg Am 2001;83(3):336345.

16. Nielsen PT, Jorgensen LN, Albrecht-Beste, Leffers AM, Rasmussen LS. Lower thrombosis risk with epidural blockade in kneearthroplasty. Acta Orthop Scand 1990;61(1):29-31.

17. Lieberman JR, Huo MM, Hanway J, Salvati EA, Sculco TP, Sharrock NE. The prevalence of deep venous thrombosis after total hip arthroplasty with hypotensive epidural anesthesia. J Bone Joint Surg Am 1994;76(3):341-348.

18. Modig J, Malmberg P., Karlström G. Effect of epidural versus general anesthesia on calf blood flow. Acta Anaesthesiol Scand 1980;24(4):305-309.

19. Zhang W, Li N, Chen S, Tan Y, Al-Aidaros M, Chen L. The effects of a tourniquet used in total knee arthroplasty: A metaanalysis. J Orthop Surg Res 2014;9(1):13.

20. Cai DF, Fan QH, Zhong HH, Peng S, Song H. The effects of tourniquet use on blood loss in primary total knee arthroplasty for patients with osteoarthritis: A meta-analysis. J Orthop Surg Res 2019;14(1):348.

21. Clarke MT, Longstaff L, Edwards D, Rushton N. Tourniquetinduced wound hypoxia after total knee replacement. J Bone Joint Surg Br 2001;83(1):40-44.

22. Aglietti $P$, Baldini A, Vena LM, Abbate R, Fedi S, Falciani M. Effeect of tourniquet use on activation of coagulation in total knee replacement. Clin Orthop Relat Res 2000;371:169-177.

23. Fukuda A, Hasegawa M, Kato K, Shi D, Sudo A, Uchida A. Effect of tourniquet application on deep vein thrombosis after total knee arthroplasty. Arch Orthop Trauma Surg 2007;127(8):671675.

24. Crenshaw A. Surgical Techniques and Approaches. DK Canale S, Jones L, editor. St 9th ed. Louis, Mosby;1998, pp. 129-142. 